\title{
Reconfiguring maritime networks due to the Belt and Road Initiative: impact on bilateral trade flows
}

\author{
Naima Saeed ${ }^{1} \cdot$ Kevin Cullinane $^{2} \cdot$ Victor Gekara $^{3} \cdot$ Prem $_{\text {Chhetri }}{ }^{3}$
}

Accepted: 21 April 2021 / Published online: 7 May 2021

(c) The Author(s), under exclusive licence to Springer Nature Limited 2021

\begin{abstract}
This paper aims to analyse the potential effects on bilateral trade movements of the reconfiguration of maritime networks brought about by the Belt and Road Initiative (BRI). The gravity model of international trade is applied to examine the hypothesized impact of maritime network reconfiguration on the bilateral trade between nine exporting countries (Egypt, Saudi Arabia, Israel, Panama, Colombia, Costa Rica, Singapore, Malaysia and Indonesia) and their 128 trading partners. The panel data on the five components of the Liner Shipping Bilateral Connectivity Index, the export value, the gross domestic product (GDP) of the nine exporting countries, the GDP of their trading partners and the maritime distance linking them to these 128 trading partners for each of the years from 2008 to 2016 are used in the analysis. The results show that the estimated coefficient for the number of transhipments is negative, revealing an inverse relationship between transhipments and bilateral exports, reconfirming that a redesign of the maritime supply chain network in response to the BRI could significantly improve bilateral export values. Furthermore, a reduction in the number of required transhipments, because of a reconfiguration of maritime networks with BRI trading partners, will improve the maritime network structure between countries located along the three strategic chokepoints: the Suez Canal, the Panama Canal, and the Strait of Malacca. In general terms, the BRI-driven reconfiguration of maritime supply networks is linked to an improvement in the productivity of nine exporting countries. An innovative gravity-based econometric model, estimated on a large set of panel data, is introduced below, aiming at the modelling of the effect of BRI on supply chain network reconfiguration.
\end{abstract}

Keywords Maritime network reconfiguration - Belt and Road Initiative $\cdot$ Bilateral exports · Gravity model · Poisson Pseudo Maximum Likelihood (PPML)

Kevin Cullinane

kevin.cullinane@gu.se

Extended author information available on the last page of the article 


\section{Introduction}

Maritime networks are logistics routes containing strategic locations as critical points of passage. These maritime networks support commercial shipping which serves the major markets of commercial trade in the world, such as Western Europe, North America, and East Asia (Rodrigue 2016). The most influential and critical maritime routes/hubs are known as chokepoints (or bottlenecks). They are not only vulnerable to global shocks, extreme weather events or social and political unrest, but also subject to capacity constraints and the possibility of severe disruption or even closure of business operations (Notteboom et al. 2020). The grounding of the large container ship "Ever Given" in late March 2021 provides irrevocable evidence for the strategic importance of these chokepoints; the ship blocked the Suez Canal to all traffic for a week, contributing to a further increase in the already very high freight rates ${ }^{1}$ (due to COVID-19), deterioration in North American port congestion, and an expected-albeit temporary-negative impact on world trade. Supply chain reconfiguration of maritime networks involves the redesign of the physical infrastructure and the patterns of material flow.

Since the early 1990s, supply chain reconfiguration has been a widely practiced strategy among many global firms to help adapt to changing supply-demand dynamics in a deregulated global market. The main driving forces behind the reconfiguration strategy include growing international competitive pressure, changing preferences relating to market requirements, developments in information and communication technology (ICT) and global freight transport systems, and increasing uncertainties in supply chain decision making processes (Arntzen et al. 1995; Lemoine and Skjoett-Larsen 2004; Van Der Vorst and Beulens 2002; Govindan et al. 2015). The main objective of reconfiguration is to improve the efficiency of global supply chains, and their effectiveness in trade facilitation and sustainability. The key objective for firms is to improve internal capabilities to better, and more productively, integrate their local supply chains into global supply chains (Lemoine and Skjoett-Larsen 2004). Thus, reconfiguration is considered an effective strategy to obtain access to the required production capability and logistics functionality at an exact point of time and location (Koren 2010).

It is expected that China's investment in strategic locations such as ports, airports and other associated transport infrastructure around the world, under its Belt and Road Initiative (BRI), will significantly transform the global maritime network. Haralambides and Merk (2020) identify four transport-linked adaptations within the BRI in order to evaluate the potential effect of the BRI on global maritime trade movements: (i) managing existing maritime routes to secure trade flows in all situations; (ii) the creation of alternative routes to avoid the possibility of over-dependence on existing routes; (iii) improving transport infrastructure to create new trade; and (iv) potential modal shifts. Cariou (2020) suggests that the new routes encompassed within the BRI could significantly impact future trade volume, direction and

1 UNCTAD, based on data provided by Clarksons Intelligence Network.

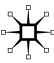


modal shifts, particularly from ocean to rail. The BRI is likely to create a Sino-centric world order to facilitate the movement of goods via designated trade corridors. China's BRI is most likely, therefore, to constitute a major disruptor of the global maritime supply chain network and, arguably, the bilateral shipping connectivity of participating countries in the BRI is expected to improve, at least with China and other countries on the BRI. In a significant way, therefore, China's BRI has the potential to result in the reorganisation and redefining of the order of global trade connectivity and the international logistics network. Consequently, this will necessitate the re-engineering of the ways in which participating countries, whether directly or indirectly, link to and operate within global supply chains.

This study provides an insight into this likely re-globalisation of trade through an examination of the potential impact of the BRI-led reconfiguration of the maritime network on bilateral trade flows. For this analysis, the focus is on nine exporting countries, based on their strategic location along the major global maritime transport superhighways. These include countries with main ports along or near the Suez Canal (Egypt, Saudi Arabia and Israel), the Panama Canal (Panama, Colombia and Costa Rica) and the Strait of Malacca (Singapore, Malaysia and Indonesia). These countries have ports in the most strategic maritime locations and constitute, therefore, key logistics hubs in global trade. However, their connectivity index levels vary widely. For instance, in 2016, the liner shipping connectivity index for Egypt was 62.49, while Israel's index was 37.36. Similarly, the index for Malaysia was 106.7 in comparison to 27.18 for Indonesia. ${ }^{2}$ Thus, the sample comprises countries with different levels of shipping connectivity.

Out of their 128 trading partners, 28 have ports located along, and are part of, the BRI (see Fig. 1). These participating countries, as shown in the map in Fig. 1 in a light red colour, are Korea, Malaysia, Cambodia, Sri Lanka, Pakistan, Bangladesh, Egypt, Turkey, Belgium, the Netherlands, Greece, Djibouti, Kenya, Tanzania, Namibia, Angola, Mauritania, Nigeria, Algeria, Senegal, Guinea, Ivory Coast, Ghana, Togo, Sao Tome, Cameroon, Gabon and Mozambique (OECD 2018; Wang et al. 2021). ${ }^{3}$

In this study, two plausible scenarios are developed to evaluate the likelihood of potential connectivity improvements from BRI investments. The first scenario assumes that the minimum number of required transhipments in the trade between the nine exporting countries and these 28 trading partners will reduce by one, while the minimum number of required transhipments in the trade with the rest of their

\footnotetext{
2 The values reported here are those from the UNCTAD Liner Shipping Connectivity Index (LSCI) published during the years covered by the study. UNCTAD has recently updated the methodology of the calculation (See Box 3.1 here https://unctad.org/webflyer/review-maritime-transport-2019) and the LSCI values published today for those years are slightly different (see https://unctadstat.unctad.org/wds/Table Viewer/tableView.aspx?ReportId=92). However, the order of magnitude and differences between the countries reported here has not changed. For our paper, we report on the LSCI and LSBCI that correspond to the components used and assessed in our model.

3 Although China has signed an MoU, before December 2017, with 64 countries along the BRI (see Chen et al., 2021), only those 28 countries that have ports located along and are part of the BRI are included (see OECD 2018).
} 


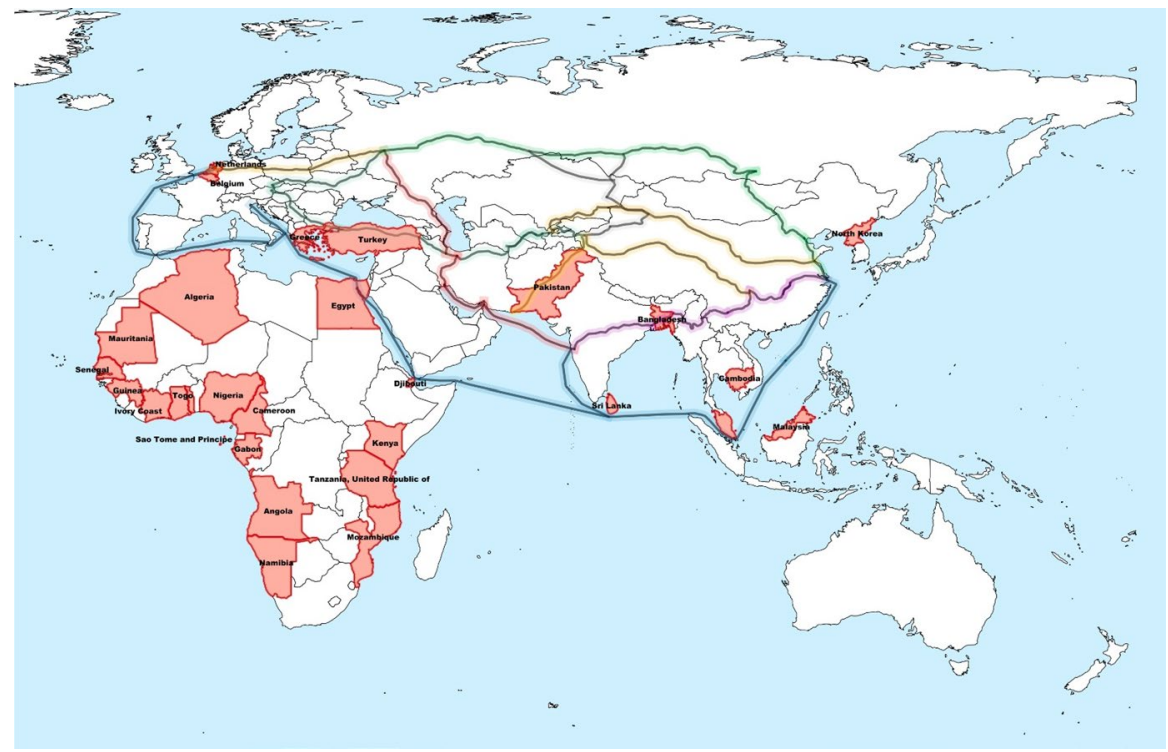

Fig. 1 The Network Configuration of the Belt and Road Initiative (key trade corridors and selected participating countries). (Source: Authors' own compilation)

trading partners remains the same. The second scenario assumes that the minimum number of required transhipments in the trade with these 28 trading partners will be zero in the long run, while the minimum number of required transhipments in the trade with the rest of the trading partners remains the same.

\section{Literature review}

\subsection{Supply chain reconfiguration}

Supply chain reconfiguration is the design process of continuous and effective adjustment of business operations to maintain productivity, efficiency, resilience, and competitiveness of supply chains, especially in the context of a globally competitive and uncertain business environment (Tian and Guo 2019). Supply chain reconfiguration involves designing supply chains to optimise performance in response to the changing domestic or international trade landscapes. The process should result in a reorganisation and repositioning of operations within the supply chain to enhance performance and, as suggested by Meixell and Gargeya (2005), to respond to a supply chain design problem. They explain that a supply chain design involves decisions regarding "the number and location of production facilities, the amount of capacity at each facility, the assignment of each market region to one or more locations, and supplier selection for sub-assemblies, components and materials" (p. 2) (see also Chopra and Meindl 2004). It is these various elements, in the production and distribution process, that are re-examined in the process of reconfiguration. 
Thus, as supply chains become more competitive and globally complex, characterised by limited visibility, and increased uncertainty and unpredictability, the need for continuous adjustment of supply chain configuration is necessary to ensure optimal productivity, performance and flexibility at all times (Beamon 1998; Oh et al. 2013; Dev et al. 2016). For this reason, over the past three decades an increasing amount of research has been dedicated towards supporting and informing businesses on how to ensure adaptability and performance through supply chain reconfiguration (Dev et al. 2016; Beamon 1998; Kristiano et al. 2012; Kirkwood et al. 2005; Chan and Chan 2010; Graves and Willems 2005; Lee 1996).

There has been a large number of studies investigating various aspects of supply chain reconfiguration. However, the majority of this research has focused on the reconfiguration of commodity supply chains (see, for example, Chunxia and Shensheng 2001; Lee et al. 2008; Osman and Demirli 2010; Kristianto et al. 2012; Dev et al. 2016; Martins et al. 2017; Jiang et al. 2018; Mondragon et al. 2018; Tian and Guo 2019; Tziantopoulos et al. 2019; Feitó-Cespón et al. 2021). This leaves the reconfiguration of services supply chains largely unexplored (Lemoine and SkjoettLarsen 2004).

While most studies on supply chain reconfiguration have focused on manufacturing, only a few have been dedicated to examining the reconfiguration of distribution, particularly in relation to transport network reconfiguration. The exception is Derigs and Illing (2013) who examine how cargo airlines may reconfigure routes in order to meet the EU's $\mathrm{CO} 2$ emissions regulation whilst maintaining profitability. They conclude that the proposed regulation will result in little or no effect towards reducing emissions and that only "drastic network reconfiguration by hub relocation" might succeed in bringing about emissions reduction as well as cost reduction (p. 526). Zhao et al. (2016) also focus on transport network reconfiguration and investigate the possibility of an integrated approach to accomplishing transport network reconfiguration and routing for synchronous evacuation during disaster situations. Similarly, the Lemoine and Skjoett-Larsen's (2004) study focuses on transport services but, rather than examining how transport routes and networks reconfigure, they examine the implications of supply chain reconfiguration on transport service demand.

Interestingly, the majority of extant literature on (transport) network reconfiguration is on internet distribution networks (e.g. Aguado et al. 2016; Ping et al. 2005; Shen and Zukerman 2012), while a search for maritime network reconfiguration highlights studies relating to shipboard electric power systems (e.g., Atteya et al. 2017; Zhao, et al. 2016; Huijuan et al. 2014; Zhang et al. 2017; Agnello et al. 2017). However, some recent research, albeit limited, has been developed which more closely focuses on maritime network reconfiguration.

A few studies have focussed on the nature of port competitiveness and its impact on the configuration of container shipping networks. In this respect, a port's accessibility to maritime networks (a more holistic concept than 'connectivity') has been identified as an important contributor to its competitive position. As such, outcomes from this body of research typically recommend that ports implement policies and actions which seek to influence the reconfiguration of maritime networks (e.g. Berli et al. 2018; Cullinane and Wang 2009, 2012; Ducruet and Notteboom 2012; Guo 
and Yang 2018; Wang and Cullinane 2008, 2014, 2016; Wilmsmeier and Notteboom 2011; Xu et al. 2020).

Dai et al. (2018) investigate shipping lines' operational cost and CO2 emissions under different geo-network configurations when an emission charge is imposed and conclude that "shipping firms' network configuration is influenced by emission charges, fuel price, port loading and unloading cost, and demand pattern of cargo transport across different markets" and that if the charge is above a certain threshold, shipping lines "will reconfigure shipping networks to minimize their costs including emission charge payments". On the other hand, Fan et al. (2010) explore the reconfiguration impact of nodal constraints (such as congestion) within the logistics channel. They suggest that the optimisation of ship size, route, port and hinterland shipping corridors have a significant impact on shipping flows.

It can be concluded, therefore, that whereas there is a large body of literature on various aspects, (e.g., maritime transport efficiency, operations optimisation, port and hinterland logistics efficiency and competitiveness, shipping operations cost, etc.) so far, there exists only a limited number of studies with a specific focus on maritime (transport) network reconfiguration, leaving a gap in the literature. More research is therefore needed to examine how international maritime transportation may be reconfigured to enhance efficiency and cost reduction in the face of growing international trade complexity and increasing international consumer demands. This research paper seeks to contribute to filling this gap by investigating the reconfiguration impact of China's Belt and Road Initiative (BRI), through which significant investment has been directed towards transport infrastructure development in key countries along the BRI, including ports and connecting hinterland roads and rail infrastructure.

\subsection{The Belt and Road Initiative}

The Belt and Road Initiative (BRI) was introduced in 2013 and officially published in 2015 by the Chinese government (NDRC 2015), with the objective of boosting regional economic cooperation through infrastructure development, in the first instance, and to enhance trade partnerships and transport connectivity, particularly to Europe but also with the rest of the world (Georgiev 2015; Lee et al. 2018; Huang 2016). Huang (2016) explains that the BRI is essentially a redefinition of the 19th Century land-based Silk Road Economic Belt (the Belt), which includes a maritime aspect-the 21st Century Maritime Silk Road (the road) (see also Du 2016; Cullinane et al. 2018).

The ambitious scale of the BRI is clear from the projected US 1 trillion commitment by the Chinese government and the involvement of at least 138 participating countries, representing over $60 \%$ of the total world population (Oliveira et al. 2020; Huang 2016). Although the broader rhetoric is about economic cooperation, the core conceptualisation of the BRI is transport infrastructure development, as well as the promotion of regional and international trade connectivity, as expressed in China's National Development and Reform Commission (see NDRC 2015, 2, see also Lee et al. 2018): 
The B\&R aims to promote the connectivity of Asian, European and African continents and their adjacent seas, establish and strengthen partnerships among the countries along the Belt and Road, set up omni-dimensional, multi-tiered and composite connectivity networks, and realize diversified, independent, balanced and sustainable development in these countries.

As illustrated on the map shown in Fig. 1, several key transport routes form the BRI. According to the OECD (2018), the land-based "Belt" revolves around six 'corridors' for economic development, namely; 1. The New Eurasian Land Bridge Economic Corridor (NELBEC); 2. The China-Mongolia-Russia Economic Corridor (CMREC); 3. the China-Central Asia-West Asia Economic Corridor (CCWAEC); 4. the China-Indochina Peninsula Economic Corridor (CICPEC); 5. the Bangladesh-China-India-Myanmar Economic Corridor (BCIMEC) and 6. The China-Pakistan Economic Corridor (CPEC). The maritime-based "Road" is a more nebulous concept, but is generally held to comprise three corridors, including first, China to the Indian Ocean, extending to Africa and Europe; China to the Pacific Ocean through the South China Sea; and a cluster of corridors including the China-Pakistan and Bangladesh-China-India-Myanmar economic corridors (Huang 2016; Lee et al. 2018; OECD 2018).

Most of the initial studies on the BRI initiative focused more on the geopolitical implications, as pointed out in Ferrari and Tei's (2020) review of the literature (see also OECD (2018) and Haralambides and Merk (2020) for an overview of the broader objectives of the BRI). However, in recent years more studies on the implications for trade and transport operations have emerged with many attempting to predict the potential impacts in terms of trade volumes and flows, and transport costs and efficiency. As pointed out by Lee et al. (2018), the BRI will most likely lead to the reconfiguration of maritime networks and alter the ways goods are transported, including changing the designations of key ports and regional hinterland corridors. When fully implemented, the BRI will not only open up and link remote and landlocked countries in developing regions like the Indian subcontinent (Palit 2017; Ranjan 2015; Karim; 2015), South-East Asia (Wang 2014; Yuzhu 2013) and Africa (Lee 2016; Brewster 2017; Chen et al. 2020), but also increase regional and international trade. Ferrari and Tei $(2020$, p. 15) argue that "the estimated amount of investment has the capability of reshaping most of the current transport infrastructure in both Asia and Europe."

One of the key outcomes sought in the BRI plan is to improve global maritime (logistics) connectivity, in particular for the countries along the BRI (Haralambides and Merk 2020). This in turn may change the patterns of transhipment to enable an efficient and cost-effective cargo movement internationally ( $\mathrm{Du} 2016$ ). For example, Lee et al. (2018) observe that the BRI-associated infrastructure developments will "have a major impact on container and liquid cargo movements in the Middle East and Europe, as well as on Shanghai's transhipment trade through the Malacca Strait" (see also Li et al. 2015; Ranjan 2015; Chen and Yang 2019). It is important to note, however, that most discussions of impacts are merely predictions and projections (see e.g., Du 2016; Lee et al. 2018; Tan and 
Zhou 2015), since the BRI's short period in existence means that many projects initiated are unlikely to have yet resulted in major outcomes.

Many countries along the BRI route anticipate improved maritime connectivity, which has the potential to boost their international trade, lower trade costs, and generally improve accessibility and integration into the global supply chain network (Hoffmann et al. 2020). After analysing the impact of five components of the LSBCI on the bilateral trade of South Africa with its 142 trading partners, Hoffmann et al. (2020, p. 496) conclude that "the number of necessary transhipments affects bilateral trade flows negatively [...] as each transhipment implies additional costs, time and risk of delays and damages" (see also Fugazza and Hofmann 2017). In their simulation of the potential trade benefits of the BRI on European trade, Herrero and Jianwei (2017) find that the benefits will mostly be reaped in relation to faster and cheaper transportation accruing from BRI-related new transport infrastructure development and/or the improvement of existing facilities; for example, in port terminals and connecting rail and road corridors. In this regard, they observe that EU countries, particularly land-locked ones, will benefit by an $8 \%$ increase in trade value. Similarly, a study by Yang et al. (2020) suggests that the impact of the new China-Europe Railway Express will be greater transport accessibility for trade, leading to higher cargo volume flows and an increased accumulation of value adding activity at an expanded Chongqing International Logistics Centre. Baniya and Rocha (2019) examine the overall impact of the BRI and suggest that, among other benefits, the associated investment and infrastructure improvement across some 71 countries will increase trade flows among participating countries by $4.1 \%$.

From a maritime transport perspective, therefore, the development of new strategic container ports, or the enhancement of existing ones alongside hinterland connectivity improvements, may lead to the reconfiguration of maritime transport routes, which could reduce or increase the minimum number of required transhipments for different countries. In this respect, this study examines the ways in which the international maritime network is likely to reconfigure in response to BRI-related infrastructure investment and the potential impact on bilateral trade flows.

\section{Methodology}

\subsection{Gravity model}

The gravity model of international trade is applied for the analysis. This model has been extensively used by researchers, especially in applied international economics (see, for example, Krisztin and Fischer 2015; Kahouli 2016; Afesorgbor 2017). The following five characteristics of the gravity model make it one of the most influential and widely used tools to examine the various determinants of international trade: First, the model is a highly intuitive tool. By applying the well-known Newton's Law of Universal Gravitation, the gravity model of trade argues that international trade between two trading partners is directly related to the product of their economic sizes, and negatively related to the square of the distance between them. Second, the gravity model is based on a sound and well-established theoretical framework 
that makes it particularly useful for examining the impact of trade policies. Third, the gravity model possesses a unique ability to simultaneously incorporate multiple units (countries, sectors, and firms) and to demonstrate the possibility of linkages between them. In this context, the model can be applied to analyse the impact of trade policy changes in the rest of the world. The fourth characteristic is its flexibility in terms of the possibility for integration within a wide range of broader general equilibrium models. Finally, one of the most salient features of the gravity model is its predictive power (Van Bergeijk and Brakman 2010; Yotov et al. 2016).

We estimate the following equation:

$$
\operatorname{In}\left(Y_{i j t}\right)=\alpha_{i t}+\beta_{j t}+\delta X_{i j t}+\varepsilon_{i j t}
$$

where the subscripts $i$ and $j$ correspond to the exporter and importer countries. $\operatorname{In}\left(Y_{i j t}\right)$ is the dependent variable, which is the value of bilateral exports from country $i$ to $j$. The parameters $\alpha_{i t}$ and $\beta_{j t}$ are exporter-time and importer-time fixed effects. These effects are included to manage the unobservable multilateral resistances, plus any other noticeable and unobservable time-varying features that are country-time (exporter and importer) specific, such as national policies and exchange rates (Anderson and van Wincoop 2003; Yotov et al. 2016). Multilateral resistances indicate the hurdles which each exporter and importer country encounter in their trade with the rest of the world, including domestic trade (Adam and Cobham 2007). Thus, exporter-time fixed effects $\left(\alpha_{i t}\right)$ capture outward multilateral resistance (exporter $i$ 's ease of market approach), and importer-time fixed effects $\left(\beta_{j t}\right)$ account for inward multilateral resistance (importer $j$ 's ease of market approach) (Yotov et al. 2016). "For instance, demand conditions prevailing at destination, or supply capacity capability characterizing source countries are controlled for" (Fugazza and Hoffmann 2017, p. 11). $X_{i j t}$ is the vector of the independent variables, which are the five components of the LSBCI; the export value, the gross domestic product (GDP) of the nine exporting countries, the GDP of their trading partners, the maritime distance, and two hypothetical variables.

\subsection{Data}

For each of the nine sample countries, therefore, data on the five components of the liner shipping bilateral connectivity index (LSBCI) were collected, as well the following additional variables: the export value to the 128 trading partners, the gross domestic product (GDP) of the nine exporting countries, and their 128 trading partners, and the maritime distances linking them for each of the years from 2008 to 2016. The United Nations Conference on Trade and Development (UNCTAD) provided the data for the five components of the LSBCI and the maritime distances. The data on export values and GDP were extracted from UN COMTRADE ${ }^{4}$ and World Bank ${ }^{5}$ websites.

\footnotetext{
4 See https://comtrade.un.org/data/ accessed 6th November, 2020.

5 See https://data.worldbank.org/indicator/NY.GDP.MKTP.KD Accessed 6th November.
} 
The following variables are included in the model:

- Transhipment: The minimum number of transhipments needed for shipment between two countries $i$ and $j$;

- Directtrans: The total number of common direct services that countries $i$ and $j$ have with third countries. This is equal to the number of alternatives a shipper faces for moving cargo from country $i$ to country $j$ with one transhipment (Hoffmann et al. 2020);

- Geometricavg: The geometric average of the total number of direct connections. This variable reflects the average of the two countries' positions in the international shipping network (Fugaza and Hoffmann 2017);

- Competition: The degree of competition, as reflected by the total number of carriers that provide services along the shipping connection between the two countries (for routes that require transhipment, the Max-Min rule is applied, i.e., the largest number on the leg with the lowest number);

- Shipsize: The size, measured in TEUs, of the largest container vessel operating on the shipping route between the country-pair (again, for routes with transhipment the Max-Min rule is applied). The five components of the LSBCI reflect how an improvement in connectivity boosts trade. For instance, more direct connections, increased competition, and greater ship size mean more containers can be moved between the country-pair.

- GDP_nine: GDP per capita of nine exporting countries.

- GDP_rest: GDP per capita of all importing countries.

- Newtrans 1: this is a hypothetical variable to analyse the impact of supply chain network redesign when the transhipments with BRI importing countries reduce by one.

- Newtrans 2: this is a hypothetical variable when there is no transhipment with BRI importing countries.

- Exports: bilateral export values of nine countries with their trading partners (only highly containerisable products, traded via the maritime mode) is taken as a dependent variable.

\section{Analysis and results}

The descriptive statistics for each of the variables are presented in Table 1. Table 2 shows the values of the correlation coefficients between the variables and their significance. There is a high correlation (0.91) between two variables, "Directtrans", and "Geometricavg" which is why "Geometricavg" has been excluded from the analysis.

Ordinary Least Square (OLS) and Poisson Pseudo Maximum Likelihood (PPML) estimation with fixed effects are applied to estimate the gravity models. In the literature, it is recommended to use the PPML estimator to account for the information contained in zero trade links and to control for the problem of heteroscedasticity in panel data (Silva and Tenreyro 2011). 
Table 1 Descriptive statistics for the panel data including two hypothetical variables

\begin{tabular}{|c|c|c|c|c|c|c|}
\hline Variables & & Mean & $\begin{array}{l}\text { Standard devia- } \\
\text { tion }\end{array}$ & Minimum & Maximum & Observations \\
\hline \multirow{3}{*}{$\begin{array}{l}\text { Export (US\$ } \\
000 \mathrm{~s})\end{array}$} & Overall & \multirow[t]{3}{*}{$7.00 \mathrm{e}+08$} & $3.72 \mathrm{e}+09$ & 2 & $6.82 \mathrm{e}+10$ & $N=9891$ \\
\hline & Between & & $3.59 \mathrm{e}+09$ & 402 & $5.82 \mathrm{e}+10$ & $n=1157$ \\
\hline & Within & & $5.86 \mathrm{e}+08$ & $-1.97 e+10$ & $1.54 \mathrm{e}+10$ & $T$-bar $=8.54883$ \\
\hline \multirow[t]{3}{*}{ Transhipment } & Overall & \multirow[t]{3}{*}{0.6515} & 0.5200 & 0 & 2 & $N=10,413$ \\
\hline & Between & & 0.4757 & 0 & 2 & $n=1157$ \\
\hline & Within & & 0.2104 & -0.2372 & 2.0960 & $T=9$ \\
\hline \multirow[t]{3}{*}{ Directtrans } & Overall & \multirow[t]{3}{*}{16.5696} & 13.4456 & 0 & 86 & $N=10,413$ \\
\hline & Between & & 12.9621 & 0.1111 & 72.4444 & $n=1157$ \\
\hline & Within & & 3.5911 & 2.2363 & 39.1252 & $T=9$ \\
\hline \multirow[t]{3}{*}{ Geometricag } & Overall & \multirow[t]{3}{*}{37.6172} & 16.4550 & 4.6904 & 102.966 & $N=10,413$ \\
\hline & Between & & 15.8272 & 6.2036 & 89.8350 & $n=1157$ \\
\hline & Within & & 4.5232 & 20.3112 & 61.0028 & $T=9$ \\
\hline \multirow[t]{3}{*}{ Competition } & Overall & \multirow[t]{3}{*}{7.5312} & 7.1613 & 0 & 70 & $N=10,413$ \\
\hline & Between & & 6.5071 & 0.7777 & 60.4444 & $n=1157$ \\
\hline & Within & & 2.9958 & -12.6909 & 27.9757 & $T=9$ \\
\hline \multirow[t]{3}{*}{ Shipsize } & Overall & \multirow[t]{3}{*}{4213.541} & 3551.137 & 0 & 19,224 & $N=10,413$ \\
\hline & Between & & 3226.267 & 226.6667 & $15,370.78$ & $n=1157$ \\
\hline & Within & & 1486.53 & -6090.681 & $15,637.87$ & $T=9$ \\
\hline \multirow[t]{3}{*}{ GDP_nine } & Overall & \multirow[t]{3}{*}{$20,165.18$} & $15,865.08$ & 2300.371 & $56,559.39$ & $N=10,413$ \\
\hline & Between & & $15,554.44$ & 3239.457 & $50,278.19$ & $n=1157$ \\
\hline & Within & & 3153.702 & 8635.508 & $26,446.39$ & $T=9$ \\
\hline \multirow[t]{3}{*}{ GDP_rest } & Overall & \multirow[t]{3}{*}{$16,216.46$} & $19,470.48$ & 86.0401 & $103,110.4$ & $N=10,341$ \\
\hline & Between & & $19,281.7$ & 119.3133 & $92,546.28$ & $n=1149$ \\
\hline & Within & & 2757.358 & -3469.111 & 29,694 & $T=9$ \\
\hline \multirow[t]{3}{*}{ Distance } & Overall & \multirow[t]{3}{*}{5420.288} & 2961.469 & 75 & 11,437 & $N=10,377$ \\
\hline & Between & & 2962.611 & 75 & 11,437 & $n=1153$ \\
\hline & Within & & 0 & 5420.288 & 5420.288 & $T=9$ \\
\hline \multirow[t]{3}{*}{ Newtrans1 } & Overall & \multirow[t]{3}{*}{0.5378} & 0.5359 & 0 & 2 & $N=10,413$ \\
\hline & Between & & 0.4977 & 0 & 2 & $n=1157$ \\
\hline & Within & & 0.1989 & -0.3510 & 1.9823 & $T=9$ \\
\hline \multirow[t]{3}{*}{ Newtrans2 } & Overall & \multirow[t]{3}{*}{0.5354} & 0.5360 & 0 & 2 & $N=10,413$ \\
\hline & Between & & 0.4984 & 0 & 2 & $n=1157$ \\
\hline & Within & & 0.1977 & -0.3534 & 1.9799 & $T=9$ \\
\hline
\end{tabular}

The results are presented in Table 3. Model 1a applies OLS estimation with importer-time and exporter-time fixed effects. Models $1 \mathrm{~b}$ and $1 \mathrm{c}$ add the transhipment variables (Model 1b when transhipment with BRI countries reduces by one figure; and Model 1c when transhipment with BRI countries is zero) and apply OLS estimation with importer-time and exporter-time fixed effects. Model 2a applies PPML estimation with importer-time and exporter-time fixed effects. Models $2 b$ and $2 \mathrm{c}$ include the transhipment variables (Model $2 \mathrm{~b}$ when transhipment with BRI 


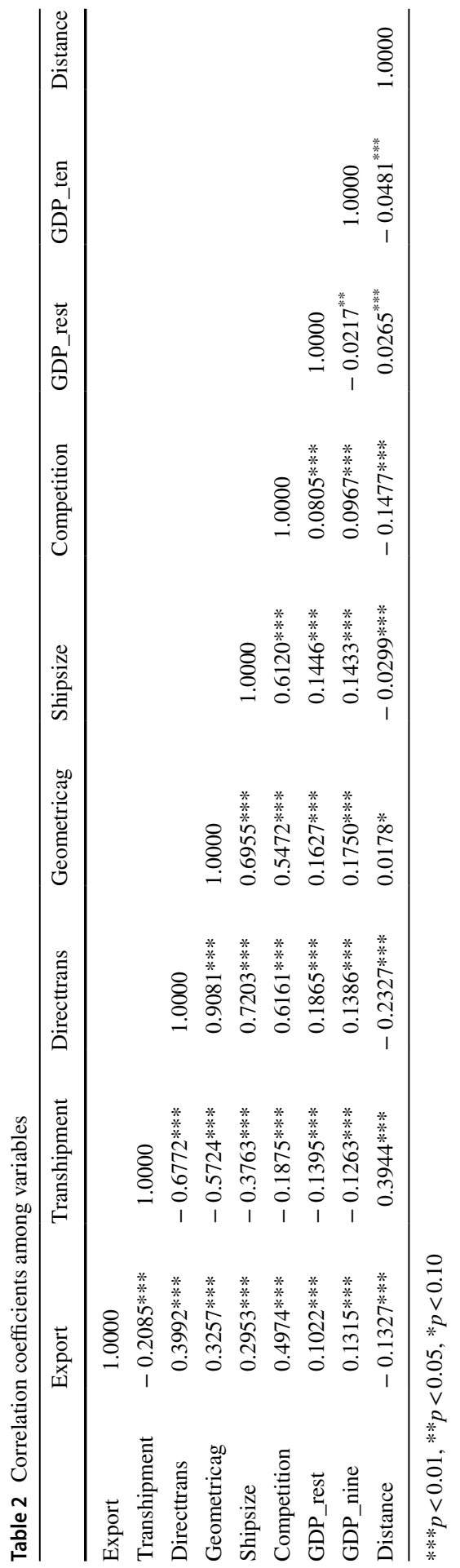

2. 


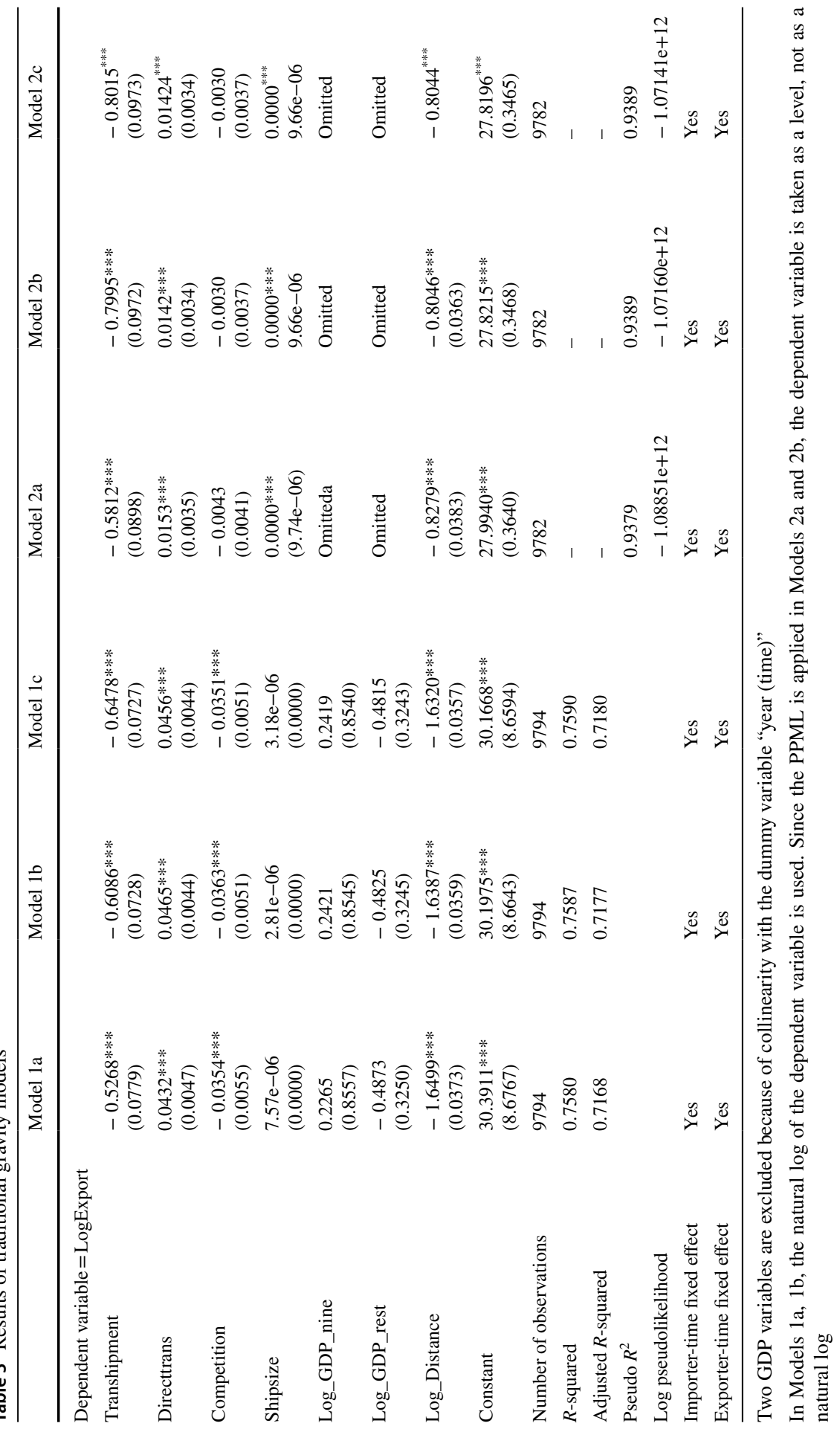


countries reduces by one figure, and Model $2 \mathrm{c}$ when transhipment with BRI countries is zero) and apply PPML estimation with importer-time and exporter-time fixed effects. As expected, the estimated coefficient for the number of transhipments is negative, revealing an inverse relationship.

The results show that out of five components of maritime connectivity, only two-the number of transhipments (Transhipment) and the number of common direct connections (Directtrans) - have a significant impact on bilateral trade in all six models. The OLS estimates show that a reduction in transhipment by one increases export value by 52\% (Model 1a). The export value increases by $60.8 \%$ when transhipment with BRI countries is reduced by one (Model 1b), and by $64.7 \%$ when transhipment with BRI countries is zero. This indicates the potential impact of the BRI on export values, purely as a consequence of improved shipping connectivity. The PPML estimates yield similar results in all three models, but the values of the coefficients are higher compared to the OLS estimates. Given that the BRI purports to enhance global maritime connectivity between countries that, in turn, is likely to increase the number of common direct connections, and yield a consequent reduction in required transhipments between nations, the plan may prove to actually promote bilateral trade.

A further detailed disaggregate analysis ${ }^{6}$ was conducted to examine the impact of a reduction in transhipment on the bilateral trade of individual nations. This analysis was carried out by dropping each of the $28 \mathrm{BRI}$ countries one at a time, to estimate the impact on the aggregate model. The results show that the top five BRI countries, which benefit the most from a reduction in transhipment, are Kenya, Pakistan, Tanzania, Sri Lanka and Angola. In contrast, the five BRI countries which benefit the least are Bangladesh, S. Korea, Cameroon, Belgium and Malaysia. One reason for this difference might be because the countries in the former category seem to be more closely linked to the BRI network, while those in the latter group are relatively more distanced, e.g., Belgium, Cameroon, and S. Korea. Another reason could be that the former category of countries already enjoy better bilateral maritime connectivity with the sample exporting countries than countries in the second category. For instance, the Liner Shipping Bilateral Connectivity Index (LSBCI) of Pakistan with the sample exporting countries for 2016 is higher compared to Bangladesh. ${ }^{7}$

The OLS estimates for the number of common direct connections (Directtrans) indicate that an increase by one unit increases the export value by $4.3 \%$ (Model 1a), by $4.6 \%$ (Model 1b) and by $4.5 \%$ (Model 1c). The results obtained from PPML estimation also demonstrate the positive effect of common direct connections, but the values of the coefficients are lower compared to the OLS estimates. The variable Competition has a negative and significant impact on trade when estimated by OLS, but its sign is negative and insignificant in PPML estimation. Having a larger number of carriers that provide services on the shipping connection between two countries may not increase export values. The variable size of the ship (Shipsize) has an insignificant effect, as the values of the coefficients are negligible. It might

\footnotetext{
${ }^{6}$ Results can be provided upon request.

7 See https://unctadstat.unctad.org/wds/TableViewer/tableView.aspx Accessed 24th November 2020.
}

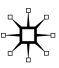


be inferred, therefore, that countries with sufficient port infrastructure to accommodate larger ships do not necessarily enhance export volumes. The variable maritime distance (Log Distance) has a negative and significant effect in all six models. This validates the hypothesis that the international trade between two trading partners is negatively related to the square of the distance between them. The greater the distance between two countries, the lower the trade, even in a highly connected globalised marketplace. However, like the variable Directtrans, the values of its coefficients are lower when estimated by PPML.

\section{Conclusion}

The sustenance of global economic order and international economic prosperity is underpinned by the rate, volumes and patterns of international trade. Considering that over $80 \%$ of international trade is carried by ocean transportation, any major reconfiguration of international maritime connectivity is likely to significantly impact on global supply chains and, by extension, globalisation itself. China's BRI, by its scale, scope and capacity, has the potential for such disruption in maritime transportation networks and trade. BRI's projects related to port development in Pakistan (Gwadar), Djibouti, Myanmar (Kyaukpyu), Greece (Piraeus), and Sri Lanka (Hambantota and Colombo) are facilitating the improvement in port infrastructure in Africa, Asia, and Europe. Chinese port operators and investors like China Ocean Shipping continue to expand their operations internationally. Because of the BRI initiative, China Ocean Shipping successfully acquired port facilities in Greece, Italy, and Spain and signed a concession agreement with Zeebrugge Port Authority to open a container terminal (Drewry Maritime Research 2017; Wei 2018).

In this regard, this paper has examined the ways in which the international maritime network is likely to be reconfigured in response to BRI-related infrastructure investment and to evaluate the potential impact on bilateral trade flows. This is the first study that examines the maritime network reconfiguration in response to the BRI and its impact on bilateral exports. The underlying study focused on nine countries, strategically located along the major global trade routes and/or along the BRI, and a selection of their exporting country partners. The nine countries considered are Egypt, Saudi Arabia, Israel, Panama, Colombia, Costa Rica, Singapore, Malaysia and Indonesia, together with their 128 trading partners.

The traditional gravity model of trade has been applied to analyse the influence of potential improvements in bilateral maritime connectivity, brought about by the BRI, on the bilateral exports of these nine countries and their 128 maritime trading partners. Justified by previous research which proved that the minimum number of required transhipments is the most influential variable in terms of its significance and magnitude (see Hoffmann et al. 2020; Saeed et al. 2020), the value of this variable has been changed in two plausible scenarios to reflect the potential improvement in maritime connectivity brought about by the BRI.

The results confirm that the reduction in transhipments under these two plausible scenarios (by one and by setting it equal to zero) significantly improves bilateral export values. Furthermore, a decrease in transhipments will change and enhance 
the maritime network structure between countries located along the three strategic chokepoints and their trading partners. In more general terms, the resulting supply chain network reconfiguration is associated with improvements in productivity and efficiency and that, more specifically, maritime network reconfiguration, as an outcome of the BRI, has the capacity to improve productivity, as manifested as gains in bilateral export values.

The study demonstrates that the maritime network reconfiguration resulting from the implementation of the BRI will have an important impact on the maritime connectivity of the selected countries. Whether the impact is great, as in the cases of Kenya, Pakistan, Tanzania, Sri Lanka and Angola, or small, as in the cases of Bangladesh, Korea, Cameroon, Belgium and Malaysia, there is evidence that the BRI will reduce the number of required transhipments between the sample nations and their trading partners and thus enhance the efficiency, and by extension, reduce the cost of trade for these countries. It, therefore, has the potential to transform the trade fortunes of many countries in significant ways, by enhancing their connectivity to the global trade superhighways. The likely eventual result is that, as other countries respond (mostly those that are not participating in the BRI), the established patterns of global trade will change.

Acknowledgements The authors are grateful to the Editor in Chief, Professor Dr. Hercules Haralambides, Dr. Jan Hoffmann at UNCTAD, and two anonymous reviewers for constructive feedback on an earlier draft of the paper. Naima Saeed acknowledges financial support from the European Union project “OpenInnoTrain” for a research stay at RMIT, Melbourne, Australia.

\section{References}

Adam, Christopher, and David Cobham. 2007. Modelling multilateral trade resistance in a gravity model with exchange rate regimes. Centre for Dynamic Macroeconomic Analysis Conference Papers 44: $1-49$.

Afesorgbor, Sylvanus Kwaku. 2017. Revisiting the effect of regional integration on African trade: evidence from meta-analysis and gravity model. The Journal of International Trade \& Economic Development 26: 133-153.

Agnello, Luca, Massimo Cossentino, Giada De Simone, and Luca Sabatucci. 2017. Shipboard power systems reconfiguration: a compared analysis of state-of-the-art approaches. Smart Ships Technology: $1-9$.

Aguado, Alejandro, Matthew Davis, Shuping Peng, Maria Victoria Alvarez, Víctor. López, Thomas Szyrkowiec, Achim Autenrieth, et al. 2016. Dynamic virtual network reconfiguration over SDN orchestrated multitechnology optical transport domains. Journal of Lightwave Technology 34 (8): 1933-1938.

Anderson, James E., and Eric Van Wincoop. 2003. Gravity with gravitas: A solution to the border puzzle. American economic review 93 (1): 170-192.

Arntzen, Bruce C., Gerald G. Brown, Terry P. Harrison, and Linda L. Trafton. 1995. Global supply chain management at Digital Equipment Corporation. Interfaces 25 (1): 69-93.

Atteya, Inji Ibrahim, Hamdy Ashour, Nagi Fahmi, and Danielle Strickland. 2017. Radial distribution network reconfiguration for power losses reduction using a modified particle swarm optimisation. CIRED-Open Access Proceedings Journal 2017 (1): 2505-2508.

Baniya, Suprabha, Nadia Rocha, and Michele Ruta. 2019. The World Bank: Trade effects of the New Silk Road: A gravity analysis.

Beamon, Benita M. 1998. Supply chain design and analysis: Models and methods. International Journal of Production Economics 55 (3): 281-294. 
Berli, Justin, Mattia Bunel, and César. Ducruet. 2018. Sea-land interdependence in the global maritime network: The case of Australian port cities. Networks and Spatial Economics 18 (3): 447-471.

Brewster, David. 2017. Silk roads and strings of pearls: The strategic geography of China's new pathways in the Indian Ocean. Geopolitics 22 (2): 269-291.

Cariou, P. 2020. Changing Demand for Maritime Trade, International Transport Forum Discussion Papers, No. 2020/04, OECD Publishing, Paris.

Chan, Hing Kai, and Felix TS. Chan. 2010. Comparative study of adaptability and flexibility in distributed manufacturing supply chains. Decision Support Systems 48 (2): 331-341.

Chen, Kang, Xu. Shihe, and Hercules Haralambides. 2020. Determining hub port locations and feeder network designs: The case of China-West Africa trade. Transport Policy 86 (2020): 9-22.

Chen, Dongxu, and Zhongzhen Yang. 2019. Investment in container ports along the maritime silk road in the context of international industry transfer: The case of the port of Colombo. Maritime Economics \& Logistics 21 (2): 241-257.

Chuanxu Wang, Hercules Haralambides and Le Zhang. 2021. Sustainable port development: the role of Chinese seaports in the 21st century Maritime Silk Road. International Journal of Shipping and Transport Logistics, *****Vol. 13, Nos. 1/2, 2021.

Chopra, Sunil, and Peter Meindl. 2004. Supply chain management: Strategy, planning and operations, 2nd ed. Upper Saddle River, NJ: Prentice Hall.

Chunxia, Lu, and Zhang Shensheng. 2001. Reconfiguration based agile supply chain system. In 2001 IEEE International Conference on Systems, Man and Cybernetics. e-Systems and e-Man for Cybernetics in Cyberspace (Cat. No. 01CH37236), vol. 2, pp. 1007-1012. IEEE.

Cullinane, Kevin P.B.., Paul Tae-Woo Lee, Zaili Yang, and Hu Zhi-Hua. 2018. China's belt and road initiative. Transportation Research Part E 117: 1-4.

Cullinane, Kevin P.B., and Yuhong Wang. 2009. A capacity-based measure of container port accessibility. International Journal of Logistics: Research and Applications 12 (2): 103-117.

Cullinane, Kevin P.B.., and Yuhong Wang. 2012. The hierarchical configuration of the container port industry: An application of multiple linkage analysis. Maritime Policy \& Management 39 (2): 169-187.

Dai, Wayne Lei, Fu. Xiaowen, Tsz Leung Yip, Hu. Hao, and Kun Wang. 2018. Emission charge and liner shipping network configuration: An economic investigation of the Asia-Europe route. Transportation Research Part A: Policy and Practice 110: 291-305.

Derigs, Ulrich, and Stefan Illing. 2013. Does EU ETS instigate Air Cargo network reconfiguration? A model-based analysis. European Journal of Operational Research 225 (3): 518-527.

Dev, Navin K., Ravi Shankar, Angappa Gunasekaran, and Lakshman S. Thakur. 2016. A hybrid adaptive decision system for supply chain reconfiguration. International Journal of Production Research 54 (23): 7100-7114.

Drewry Maritime Research. 2017. Ports and terminal insight. Fourth quarter: Quarterly.

Du, Michael M. 2016. "China's “One Belt, One Road" initiative: Context, focus, institutions, and implications. The Chinese Journal of Global Governance 2 (1): 30-43.

Ducruet, César., and Theo Notteboom. 2012. The worldwide maritime network of container shipping: Spatial structure and regional dynamics. Global Networks 12 (3): 395-423.

Fan, Lei, William W. Wilson, and Denver Tolliver. 2010. Optimal network flows for containerized imports to the United States. Transportation Research Part E: Logistics and Transportation Review 46 (5): 735-749.

Feitó-Cespón, Michael, Yasel Costa, Mir Saman Pishvaee, and Roberto Cespón-Castro. 2021. A fuzzy inference based scenario building in two-stage optimization framework for sustainable recycling supply chain redesign. Expert Systems with Applications 165 (2021): 113906.

Ferrari, Claudio, and Alessio Tei. 2020. Effects of BRI strategy on Mediterranean shipping transport. Journal of Shipping and Trade 5 (1): 1-18.

Fugazza, Marco, and Jan Hoffmann. 2017. Liner shipping connectivity as determinant of trade. Journal of Shipping and Trade 2 (1): 1-18.

Georgiev, Georgy Tchankov. 2015. "The Chinese "One Belt, One Road" initiative: New opportunities for the European Union and its neighbours in the Black Sea region. KSI Transactions on Knowledge Society 8 (2): 33-40.

Govindan, Kannan, Hamed Soleimani, and Devika Kannan. 2015. Reverse logistics and closed-loop supply chain: A comprehensive review to explore the future. European Journal of Operational Research 240 (3): 603-626. 
Graves, Stephen C., and Sean P. Willems. 2005. Optimizing the supply chain configuration for new products. Management Science 51 (8): 1165-1180.

Guo, Liquan, and Zhongzhen Yang. 2018. Evaluation of foreign trade transport accessibility for Mainland China. Maritime Policy \& Management 45 (1): 34-52.

Haralambides, Hercules, and Olaf Merk. 2020. The Belt and Road Initiative: Impacts on global maritime trade flows, international transport forum discussion papers 2020/02. Paris: OECD Publishing.

Herrero, Alicia Garcia, and Xu. Jianwei. 2017. China's belt and road initiative: Can Europe expect trade gains? China \& World Economy 25 (6): 84-99.

Hoffmann, Jan, Naima Saeed, and Sigbjørn Sødal. 2020. Liner shipping bilateral connectivity and its impact on South Africa's bilateral trade flows. Maritime Economics \& Logistics 22 (3): 473-499.

Huang, Yiping. 2016. Understanding China's Belt \& Road initiative: Motivation, framework and assessment. China Economic Review 40: 314-321.

Huijuan, S., P. Chunhua, and Y. Tingfang. 2014. A three-phase equilibrium reconfiguration strategy for distribution network. Power System Technology 38: 789-794.

Jiang, Zhengqian, Hui Wang, Qi Tian, and Weihong Guo. 2018. Co-design of supply chain network and subassembly planning considering the reconfiguration of supply chain structure for factory-in-a-box manufacturing. In ASME 2018 13th International Manufacturing Science and Engineering Conference. American Society of Mechanical Engineers Digital Collection.

Kahouli, Bassem. 2016. Regional integration agreements, trade flows and economic crisis: A static and dynamic gravity model. International Economic Journal 30 (4): 450-475.

Karim, Mohd Aminul. 2015. China's proposed maritime silk road: Challenges and opportunities with special reference to the Bay of Bengal Region. Pacific Focus 30 (3): 297-319.

Kirkwood, Craig W., Matthew P. Slaven, and Arnold Maltz. 2005. Improving supply-chain-reconfiguration decisions at IBM. Interfaces 35 (6): 460-473.

Koren, Yoram. 2010. The global manufacturing revolution: product-process-business integration and reconfigurable systems. Vol. 80. John Wiley \& Sons.

Kristianto, Yohanes, Angappa Gunasekaran, Petri Helo, and Maqsood Sandhu. 2012. A decision support system for integrating manufacturing and product design into the reconfiguration of the supply chain networks. Decision Support Systems 52 (4): 790-801.

Krisztin, Tamás, and Manfred M. Fischer. 2015. The gravity model for international trade: Specification and estimation issues. Spatial Economic Analysis 10 (4): 451-470.

Lee, Hau L. 1996. Effective inventory and service management through product and process redesign. Operations Research 44 (1): 151-159.

Lee, Paul Tae-Woo. 2016. China's growing engagement in the emerging maritime logistics market in Africa. In dynamic shipping and port development in the globalized economy, 39-68. London: Palgrave Macmillan.

Lee, Harry, Ali Farhoomand, and Phoebe Ho. 2008. Innovation through supply chain reconfiguration. MIS Quarterly Executive 3 (3): 4.

Lee, Paul Tae-Woo., Hu. Zhi-Hua, Sang-Jeong. Lee, Kyoung-Suk. Choi, and Sung-Ho. Shin. 2018. Research trends and agenda on the Belt and Road (B\&R) initiative with a focus on maritime transport. Maritime Policy \& Management 45 (3): 282-300.

Lemoine, Olga W., and Tage Skjoett-Larsen. 2004. Reconfiguration of supply chains and implications for transport. International Journal of Physical Distribution \& Logistics Management 2004: 793-810.

Li, Peiyue, Hui Qian, Ken WF. Howard, and Wu. Jianhua. 2015. Building a new and sustainable "Silk Road economic belt.” Environmental Earth Sciences 74 (10): 7267-7270.

Martins, Sara, Pedro Amorim, Gonçalo Figueira, and Bernardo Almada-Lobo. 2017. An optimizationsimulation approach to the network redesign problem of pharmaceutical wholesalers. Computers \& Industrial Engineering 106: 315-328.

Meixell, Mary J., and Vidyaranya B. Gargeya. 2005. Global supply chain design: A literature review and critique. Transportation Research Part E: Logistics and Transportation Review 41 (6): 531-550.

Mondragon, Adrian E., Christian E. Coronado, Coronado Mondragon, Paul J. Hogg, and Nuria Rodríguez-López. 2018. A design process for the adoption of composite materials and supply chain reconfiguration supported by a software tool. Computers \& Industrial Engineering 121: 62-72.

NDRC. 2015. Vision and Actions on Jointly Building Silk Road Economic Belt and 21st-Century Maritime Silk Road, Beijing. The National Development and Reform Commission (NDRC). Ministry of Foreign Affairs and Ministry of Commerce of the People's Republic of China with State Council. March 28. 
Notteboom, Theo. Athanasios Pallis and Jean-Paul Rodrigue. 2020. Port Economics, Management and Policy, Routledge, New York, Forthcoming, https://porteconomicsmanagement.org/?page_ $\mathrm{id}=317$.

OECD. 2018. China's Belt and Road Initiative in the Global Trade, Investment and Finance Landscape, 3-46. https://www.oecd.org/finance/Chinas-Belt-and-Road-Initiative-in-the-global-tradeinvestment-and-finance-landscape.pdf

Oh, Seungjin, Kwangyeol Ryu, and Mooyoung Jung. 2013. Reconfiguration framework of a supply network based on flexibility strategies. Computers \& Industrial Engineering 65 (1): 156-165.

Oliveira, Gustavo, and de LT, Galen Murton, Alessandro Rippa, Tyler Harlan, and Yang Yang. . 2020. China's Belt and Road Initiative: Views from the ground. Political Geography 82: 102225 (Forthcoming).

Osman, Hany, and Kudret Demirli. 2010. A bilinear goal programming model and a modified Benders decomposition algorithm for supply chain reconfiguration and supplier selection. International Journal of Production Economics 124 (1): 97-105.

Palit, Amitendu. 2017. India's economic and strategic perceptions of China's maritime silk road initiative. Geopolitics 22 (2): 292-309.

Ping, Li, Lu Wenjuan, and Sun Zengqi. 2005. Transport layer protocol reconfiguration for networkbased robot control system. In Proceedings. 2005 IEEE Networking, Sensing and Control, pp. 1049-1053. IEEE, 2005.

Ranjan, Alok. 2015. The China-Pakistan economic corridor: India's options. Institute of Chinese Studies 10 (1): 1-25.

Rodrigue, Jean-Paul. 2016. The geography of transport systems. Taylor \& Francis.

Saeed, Naima, Kevin Cullinane, and Sigbjørn Sødal. 2020. Exploring the relationships between maritime connectivity, international trade and domestic production. Maritime Policy \& Management 2020: 1-15. https://doi.org/10.1080/03088839.2020.1802783.

Shen, Gangxiang, and Moshe Zukerman. 2012. Spectrum-efficient and agile CO-OFDM optical transport networks: Architecture, design, and operation. IEEE Communications Magazine 50 (5): 82-89.

Silva, JMC Santos., and Silvana Tenreyro. 2011. Further simulation evidence on the performance of the Poisson pseudo-maximum likelihood estimator. Economics Letters 112 (2): 220-222.

Tan, X.J., and M.R. Zhou. 2015. Export potential of 21st-century maritime silk road and its determinants: An empirical research based on stochastic frontier gravity model. Journal of International Trade 2 : 3-12.

Tian, Qi., and Weihong Guo. 2019. Reconfiguration of manufacturing supply chains considering outsourcing decisions and supply chain risks. Journal of Manufacturing Systems 52: 217-226.

Tziantopoulos, Konstantinos, Naoum Tsolakis, Dimitrios Vlachos, and Loukas Tsironis. 2019. Supply chain reconfiguration opportunities arising from additive manufacturing technologies in the digital era. Production Planning \& Control 30 (7): 510-521.

Van Bergeijk, Peter AG, and Steven Brakman, eds. 2010. The gravity model in international trade: Advances and applications. Cambridge University Press.

Van Der Vorst, J.G., and A.J. Beulens. 2002. Identifying sources of uncertainty to generate supply chain redesign strategies. International Journal of Physical Distribution \& Logistics Management. 32 (6): 409-430.

Wang, Jinbo. 2014. One Belt One Road Initiative and ASEAN's regional integration China. Beijing: Social Sciences Academic Press.

Wang, Yuhong, and Kevin P.B.. Cullinane. 2008. Measuring container port accessibility: An application of the Principal Eigenvector Method (PEM). Maritime Economics \& Logistics 10 (1): 75-89.

Wang, Yuhong, and Kevin P.B.. Cullinane. 2014. Traffic consolidation in East Asian container ports: A network flow analysis. Transportation Research Part A: Policy and Practice 61: 152-163.

Wang, Yuhong, and Kevin P.B.. Cullinane. 2016. Determinants of port centrality in maritime container transportation. Transportation Research Part E: Logistics and Transportation Review 95: 326-340.

Wei, Z. 2018. Cosco's presence in Zeebruge fortifies its European Belt and Road. Shipping and Finance 260: 6 .

Wilmsmeier, Gordon, and Theo Notteboom. 2011. Determinants of liner shipping network configuration: A two-region comparison. GeoJournal 76 (3): 213-228.

Xu, Mengqiao, Qian Pan, Alessandro Muscoloni, Haoxiang Xia, and Carlo Vittorio Cannistraci. 2020. Modular gateway-ness connectivity and structural core organization in maritime network science. Nature Communications 11 (1): 1-15. 
Yang, Zhongzhen, Yu. Sun, and Paul Tae-Woo. Lee. 2020. Impact of the development of the ChinaEurope Railway Express: A case on the Chongqing international logistics center. Transportation Research Part A: Policy and Practice 136: 244-261.

Yotov, Yoto V., Roberta Piermartini, José-Antonio. Monteiro, and Mario Larch. 2016. An advanced guide to trade policy analysis: The structural gravity model. Geneva: World Trade Organization.

Yuzhu, Wang. 2013. The RCEP initiative and ASEAN centrality. China Int'l Stud. 42: 119-132.

Zhao, Xing, Gang Ren, and Zheng-feng Huang. 2016. Optimizing one-way traffic network reconfiguration and lane-based non-diversion routing for evacuation. Journal of Advanced Transportation 50 (4): 589-607.

Zhang, Lingjie, Jianbo Sun, and Chen Guo. 2017. A novel multi-objective discrete particle swarm optimization with elitist perturbation for reconfiguration of ship power system. Polish Maritime Research 24 (s3): 79-85.

Publisher's Note Springer Nature remains neutral with regard to jurisdictional claims in published maps and institutional affiliations.

\section{Authors and Affiliations}

\section{Naima Saeed ${ }^{1} \cdot$ Kevin Cullinane $^{2} \cdot$ Victor Gekara $^{3} \cdot$ Prem Chhetri $^{3}$}

1 Department of Working Life and Innovation, School of Business and Law, University of Agder, Grimstad, Norway

2 Department of Business Administration, School of Business, Economics and Law, University of Gothenburg, Gothenburg, PO BOX 610, Gothenburg, Sweden

3 School of Accounting, Information Systems, and Supply Chain, RMIT University, Melbourne, Australia 